\title{
By Way of Introduction: Colombia as a Field of Study
}

Colombia is today the least studied of the major Latin American countries, and probably the least understood. It has attracted the attention of specialists in Latin American literature, in good part thanks to its Nobel prize-winning novelist, Gabriel García Márquez; economists have taken note of its slow but steady economic growth, in a region better known for sharp (and in recent years mostly downward) fluctuations; and a number of political scientists have been intrigued by the peculiarities of its traditional two-party system. Nevertheless, in the papers presented at scholarly meetings and the articles published in scholarly journals, Colombia is featured far less frequently than Brazil or Mexico or Argentina or even, say, Chile or Peru. In the field of history specifically, the only English-language survey is a longoutdated English translation of a Colombian secondary text, ${ }^{1}$ whereas at least four modern English-language histories are available on Peru. Meanwhile, at the level of popular impressions-in the United States and Western Europe-the name Colombia suggests mainly drug trafficking and endemic violence. If anything more positive comes to mind, it is the familiar Juan Valdez of the Colombian coffee growers' advertising, whose image is really that of a stereotypical Latin American peasant farmer.

Colombia deserves better than this, if only for reasons of size. It is the fourth largest Latin American nation, and it is the third most populous. It had actually been third in population at the time of independence, exceeded only by Mexico and Brazil. Argentina then moved ahead on the basis of a massive influx of late-nineteenth- and earlytwentieth-century immigration such as Colombia never received, but in the past year or so Colombia has edged ahead again. In gross production it is only fifth, exceeded also by Venezuela, but it occupies first place as an exporter of such disparate commodities as emeralds, books, processed cocaine, and cut flowers. 
If, in spite of such claims on the attention of the outside world, Colombia still does not receive its fair share of scholarly attention, one reason undoubtedly is that the pervasive image of violence leads fainthearted investigators to turn elsewhere. Another, in the view of historian Charles Bergquist, is that Colombia does not fit the stereotypes and "models" conventionally used in discussions of Latin America. ${ }^{2}$ After all, what is a Latin Americanist to do with a country where military dictators are almost unknown, the political left has been congenitally weak, and such phenomena as urbanization and industrialization never spawned a "populist" movement of lasting consequence? Actually, for a student of the nineteenth century, Colombia is perhaps the most stereotypical country of all, with its long string of civil wars between Liberals and Conservatives, its retrograde clericalism and radical anticlericalism, all in a context of socioeconomic stagnation. But even scholars who work on the previous century will often choose their country of specialization on the basis of current headlines.

The problem of Colombia's image as a nation is compounded by ambivalent characteristics of the Colombians themselves. Quite apart from their tendency in recent years to take the lead in underscoring negative aspects of the national panorama, they continue to exhibit major differences along the lines of class, region, and in some cases ethnicity. It is thus a commonplace to say (with Colombians often saying first and loudest) that the country lacks a true national identity or a proper spirit of nationalism, at least as compared to most of its Latin American neighbors. Indeed, hyperbolic nationalism is not common in Colombia; and the national character, if such a thing can be said to exist, is a composite of sometimes contradictory traits. However, both the costeño (or denizen of the Caribbean coast) and the cachaco (from Bogotá or more generally the Andean interior), who profess to have almost nothing in common, make much the same complaints about the country's society and institutions, and do so within a common frame of reference.

For better or worse, Colombia does exist as a nation in the world today. The people and territory known as Colombian have not arrived at this status by an easy path; they have been torn by social, cultural, political, and regional antagonisms and misunderstandings. Yet the story consists of much more than lives lost and opportunities wasted. There have been accomplishments, too, including a remarkably vigor- 
ous output of literature and art. Colombians have also shown time and again the ability to recover from terrible predicaments and to continue their daily round of activities under circumstances that to the outside observer might have seemed hopeless. A skill at "muddling through" is certainly one of the traits to be included in any putative model of the national character.

The account that follows, of Colombia's emergence as a modern nation, is the end result of a personal association with Colombia and Colombians that by now goes back almost half a century. It does not pretend to be a wholly objective story. Whether or not full scholarly detachment is even desirable, in practice it is not humanly possible, and I do not claim to be unbiased where Colombia is concerned. I have had my share of bad experiences in that country as elsewhere, and I have seen things that I would rather not have seen; but I have made firm friends there and have come to love the sights and sounds and smells that assault my senses whenever I again set foot on Colombian soil. I have also observed that the great majority of Colombians (trite as it may be to say so) are peaceable, courteous, and not engaged in any kind of violent or criminal activity.

I still do not claim to understand Colombia as well as someone who was born into the culture and has lived there always, though at times my condition as a foreigner may actually help me see a few things more clearly. I have naturally been helped even more by a host of other people, from clerical personnel to distinguished scholars, Colombian and non-Colombian, so numerous that it is better not even to attempt a list of acknowledgments. Either I would inadvertently leave some names out or I would need too many pages. For comparable reasons, of fearing to do too little or too much, I have mostly omitted reference notes, documenting only quotations, statistical data (so that anyone who wishes can check on them), and certain special cases. Some reviewers and other readers will probably object, but the publisher did not, and cutting down on notes does leave more room for text.

I must nevertheless acknowledge at least the help of my immediate family, all of whom have spent time in Colombia with me (one was born there). Above all, I pay a tribute of gratitude to my wife, whom I first dragged off to Colombia in the aftermath of the Bogotazo-the explosion of urban rioting that shook the Colombian capital in April 1948-when I was a graduate student setting forth to do Ph.D. research on a wholly inadequate stipend. Her initial exposure proved 
traumatic, but she kept going back and has come to love the country too; hers have been a second pair of eyes through which I have been able to look at the Colombian scene over the years.

David Bushnell

Gainesville, Florida, 1992 